\title{
Enhancing Mathematical Communication in the Classroom: A Case Study
}

\author{
Le Thai Bao Thien Trung ${ }^{1}$, Phat Vinh Vuong ${ }^{2}$, Le Do Huyen Trang ${ }^{3}$, Nguyen Phu Loc ${ }^{4, *}$ \\ ${ }^{1}$ Department of Mathematics, Ho Chi Minh City University of Education, Vietnam \\ ${ }^{2}$ Faculty of Education, An Giang University -Viet Nam National University Ho Chi Minh City, Vietnam. \\ ${ }^{3}$ Cat Lai Junior High School, Ho Chi Minh City, Vietnam \\ ${ }^{4}$ School of Education, Can Tho University, Vietnam
}

Received December 16, 2019; Revised March 12, 2020; Accepted March 19, 2020

Copyright $\odot 2020$ by authors, all rights reserved. Authors agree that this article remains permanently open access under the terms of the Creative Commons Attribution License 4.0 International License

\begin{abstract}
Mathematical communication competence was mentioned the first time in the Mathematics curriculum of Vietnam, which was published in 2018. It includes different skills such as listening, reading, presenting, expressing mathematical ideas, and knowing how to use mathematical language to communicate, discuss interaction with other people. The problem is how to organize teaching to promote mathematical communication. In 2004, Radford and Demers based on the theory of Zones of Proximal Development [12] to develop a teaching strategy called the fourth strategy [9]. This teaching strategy has seven steps; it provides groups of the student with different activities to discuss, exchange, review their learning products. We have adopted this teaching strategy in a teaching situation about the concept of function in junior high school in Vietnam. Twelve students who participated in our study case worked in pairs. This teaching process focused on each group of two students reviewing products of another and basing on comments from other groups to improve their products. Furthermore, our teaching situation puts students in front of the various representations of function and thus enhances the use of mathematical language and mathematical communication for students. The results of our study showed that the teaching strategy of Radford and Demers increased students' mathematical communication. Lessons drawn from the study are that this strategy is really an effective teaching method if teachers assign open problems that stimulate the curiosities of students; in the classroom, they feel free and confident in discussion; if these conditions are met, students who learn in this approach will acquire and reinforce the knowledge as a result of a mathematical communication process.
\end{abstract}

Keywords Mathematical Competence, Mathematical Communication, Teaching Function, Mathematics
Education

\section{Introduction}

On December 26, 2018, the Ministry of Education and Training of Vietnam issued a new general education curriculum and subject curriculums, including Mathematics [6]. With this new curriculum, the Vietnamese National Assembly for the first time passed a resolution on a curriculum that could have multiple textbooks. It means that other institutions, not only the Educational publisher, can write textbooks. The most significant difference in the mathematics curriculum compared with the previous programs is the appearance of the term "competence" in the first objective. "Forming and developing mathematical competencies includes the following core elements: competence of thinking and mathematical reasoning, mathematical modelling competence, mathematical problem-solving competence, mathe matical communication competence, competence in using mathematical tools and means" [7, p.6]. The Math curriculum describes the levels that need to be reached at the end of Primary, Junior high school and high school for the four competencies. Accordingly, mathematical communication competence includes the following expressions:

- "Listening comprehension, reading comprehension and taking notes of necessary mathematical information presented in written or oral form.

- Presenting, expressing (speaking or writing) mathematical contents, ideas and solutions in interaction with others (with appropriate requirements for completeness and accuracy). 
- Using mathematical language effectively (numbers, letters, symbols, charts, graphs, logical links, etc.) in combination with natural language or physical movements when presenting, explaining and evaluating mathematical ideas in interaction (discussion, debate) with others.

- Demonstrating confidence when presenting, expressing, posing questions, discussing and debating content and ideas related to Mathematics." [7, p.13].

One challenge is to help teachers organize teaching so that students reach the levels described in this competency. In this context, we will pay attention to the question: How to develop mathematical communication competence for junior high schoolstudents in teaching function concepts?

\section{Theoretical Framework}

\subsection{Communication Standard of NCTM (2000)}

National Council of Teachers of Mathematics (NTCM 2000) has published work on "Principles and Standards for school mathematics" for curriculum from pre-kindergarten through grade 12. Related to communication in teaching math, NTCM (2000) suggested that Instructional programs should help all students [8]:

- "organize and consolidate their mathematical thinking through communicative activities;

- communicate their mathematical thinking coherently and clearly to peers, teachers, and others;

- $\quad$ analyze and evaluating the mathematical thinking and strategies of others;

- use the mathematical language to express mathematical ideas precisely" [8, p.60].

According to NCTM (2000), during adolescence, students are often reluctant to do anything that makes them stand out from the group, and many of them often feel hesitant to express their thoughts to others. They feel pressured to be compared with their peers. They want to find the right friends for themselves. As such, junior high school students are suitable for working in pairs because they can come up with different ideas, discuss carefully in groups before speaking in front of the class [8].

\subsection{Teaching Process of Radford and Demers}

With the goal of teaching to promote positive activities of students, many researchers have approached constructivist theory [3], J. Stanny [10] believed that learning activities should include: activating prior knowledge, creating surprise,; applying and evaluating the new knowledge including a reflective closing assignment. Hartle et al (2012) argued that teaching methods based on adaptation must be: eliciting prior knowledge, creating cognitive dissonance, applying new knowledge with feedback, reflecting on learning [1]. In 2019, Loc [4], and Loc \& Hang [5] came up with a 7-step teaching model in which they approached two key processes: "assimilation" and "accommodation"; Experimental teaching has shown its feasibility. In the above teaching process, the authors also pay some attention to the social interaction, but not really a solution for strengthening social interaction. A teaching model of the two authors Radford \& Demers (2004), with the approach to Vygostky's social constructivism, emphasized the student's communication and interaction during their process of cognitive development or problem-solving [9]. In their work, Radford \& Demers (2004) introduced and commented on teaching strategies that promote mathe matical communication. These strategies are understood as pedagogical decisions to give students an environment to work together and to form concepts through communication. In order to enhance mathematical communication in the classroom, we pay special attention to the fourth strategy of Radford \& Demers (2004), which was developed on the basis of the Zone of Proximal Development concept, which was introduced by Vygotsky.

Below are the steps of the fourth strategy [9]:

1. "Presentation by the teacher of the mathematical activity to be done.

2. Work in s mall groups to discuss and obtain results that must be carefully justified with convincing mathematical arguments.

3. Exchange between groups of results obtained and justifications provided. Study of solutions and arguments provided by other groups.

4. Meeting between the groups who exchanged their solutions to discuss the strengths and weaknesses of the solutions and their arguments.

5. Return to work in small groups to re-write the mathematical solutions and arguments in a more refined way, taking into account the discussion with the other groups

6. Discussion conducted by the teacher about the results obtained" [9, p. 30].

These authors argued that teaching with a fourth strategy will be in line with Vygotsky's suggestion in the sense that students should develop their concepts so they can solve problems autonomously by helping the m spread through the zones of proximal development (ZPD) [11, 12]. The strategy will bring students to face problems where their solutions go beyond the current conceptual level but become feasible through collaboration with classmates or teachers [2].

Accordingly, each step in strategy helps students experience a ZDP in their conceptual development goals (see Figure 1). 


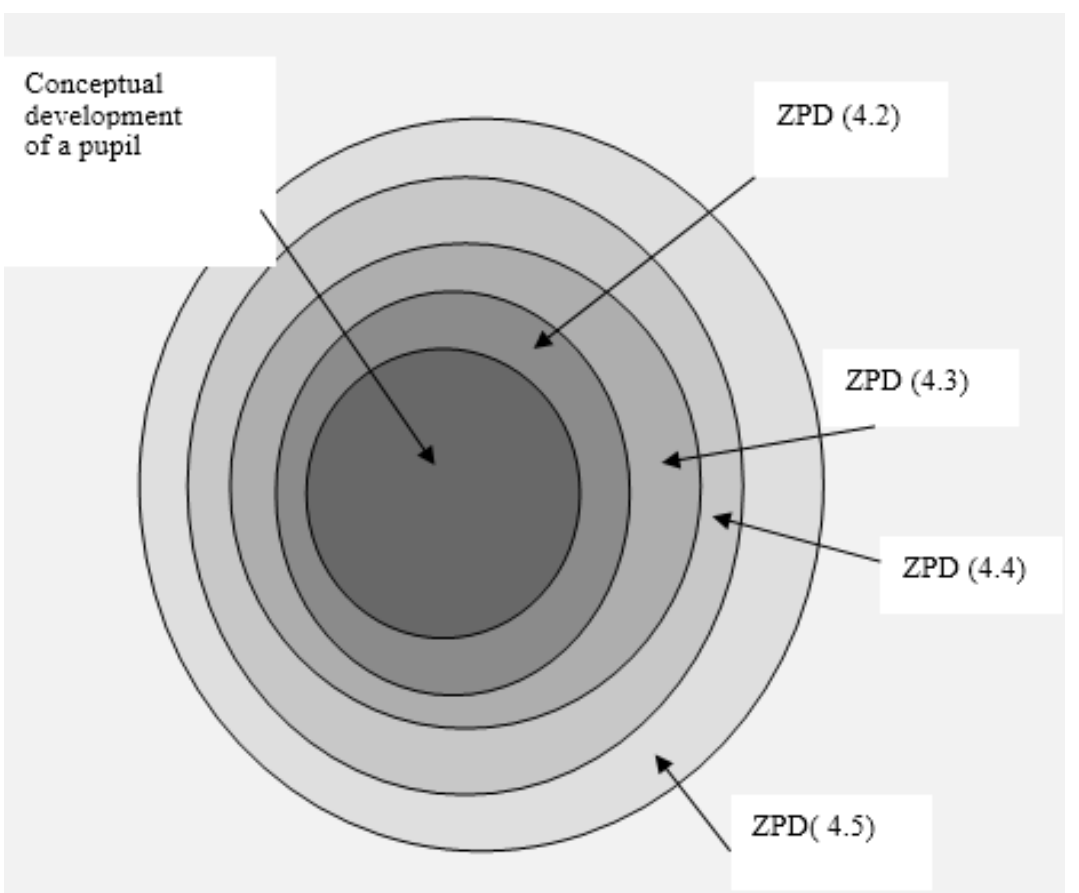

Figure 1. Teaching strategy 4 as a producer of interlocking proximal development zones. The ZPD region (4.2) corresponds to the proximal development zone generated by step 4.2 of strat egy 4. The ZPD region (4.3) corresponds to that generated by step 4.3, etc (Radford \& Demers 2004 , p. 31)

\section{Research Purpose}

We used a teaching situation about function concept, which is organized according to the $4^{\text {th }}$ strategy of Radford $\&$ Demers (2004) to pro mote mathe maticalcommun ication for students. We considered how students demonstrate their ability to communicate mathematically in a teaching situation.

\section{Methodology}

\subsection{Research Subject}

An experiment took place in 90 minutes and was conducted in 12 students of 9th-grade students of Luong Dinh Cua Junior High School (HCM City) around the end of July 2018. The school was a public school in Ho Chi Minh City. In big cities of Vietnam, 9th-grade students often prepare for exams to grade 10 public schools so they will voluntarily register some courses during the summer vacation before the school year. We randomly selected a class which prepare for 9th grade in the summer of 2018 and invited students to voluntarily participate in the experiment. Twelve (over 20) students in this class agreed to participate.

\subsection{The Problem Used for Experimental Teaching}

This context in Figure 2 is used for teaching the "function concept" in $9^{\text {th }}$ grade in junior secondary schools of Vietnam. This situation can be considered a real situation. The situation calls for the use of a function to describe the variation, depending on the volume, on the length of the square side to be cut at the four corners of the paper. For $9^{\text {th }}$ grade curriculum, in order to find out the answer to the above problem, Vietnamese students construct a formu la for calcu lating the volu me of the bo $\mathrm{x}$ in a variable $x(V=(30-2 x)(30-2 x) x)$, find the answer by giving $\mathrm{x}$ some different values and calculating corresponding $V$; the result of each case will be written down in the following table 1 in the answer sheet 1 (see Appendix). 


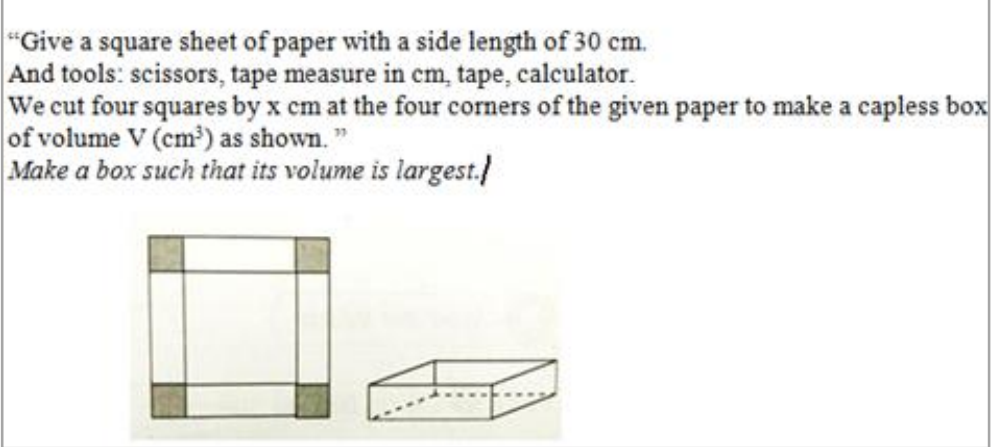

Figure 2. The problem used for tryout

Table 1. Answering sheet for students

\begin{tabular}{|l|l|l|}
\hline & $\mathrm{x}(\mathrm{cm})$ & $\mathrm{V}\left(\mathrm{cm}^{3}\right)$ \\
\hline Box 1 & & \\
\hline Box 2 & & \\
\hline Box 3 & & \\
\hline Box 4 & & \\
\hline
\end{tabular}

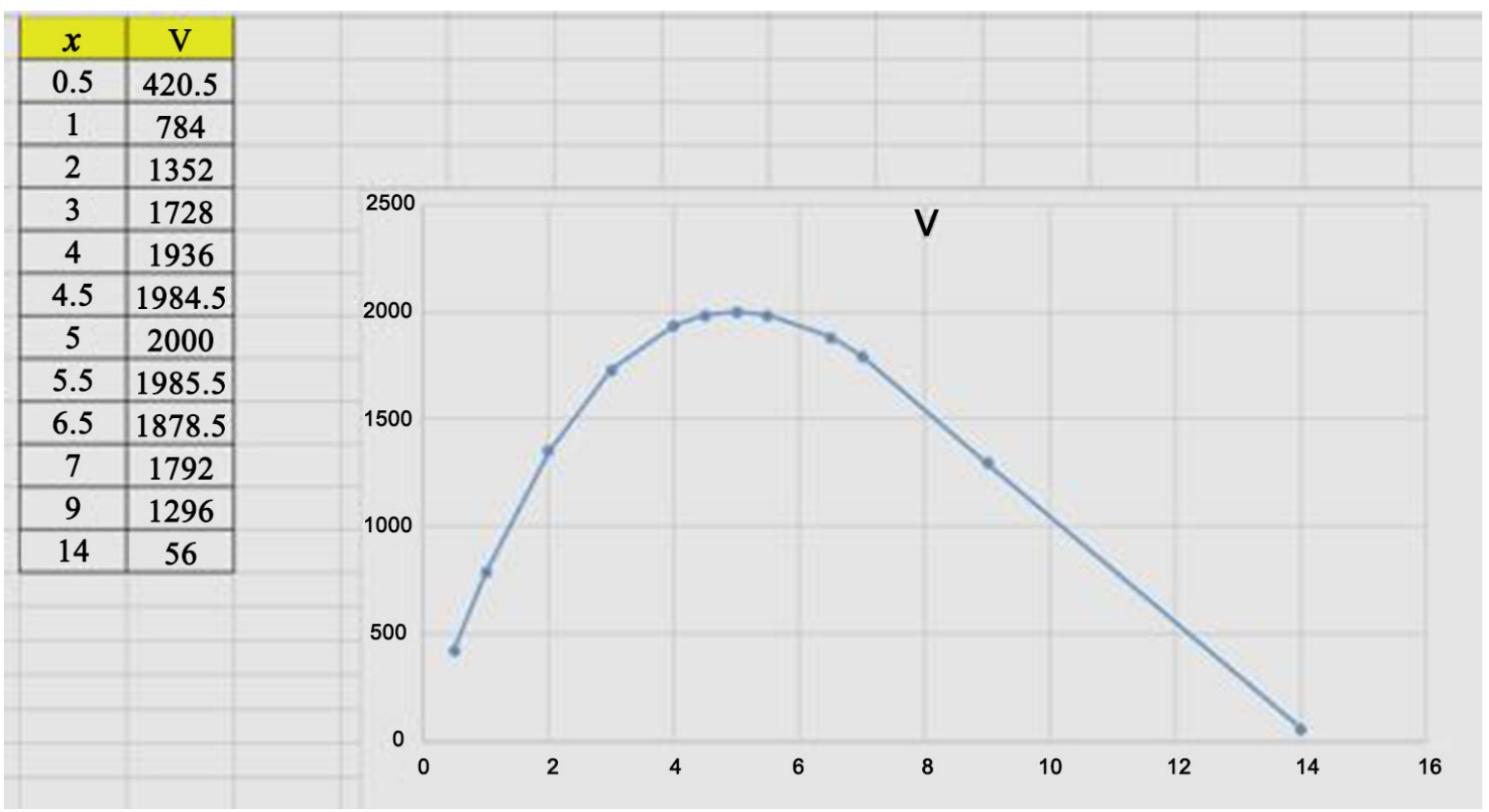

Figure 3. Graphical representation of the volume function

In order to choose the size of a square paper, we could consider a generalization. If the square paper is sized $S \mathrm{~cm}$, the box's volume will be $V=x(S-2 x)^{2} \mathrm{~cm}^{3}$ where $0<x<$ $S / 2$. Therefore, $V$ reaches its maximum value when $\mathrm{x}$ equals $\mathrm{S} / 6$. With the choice $\mathrm{S}=30 \mathrm{~cm}$, maximu $\mathrm{m}$ of $\mathrm{V}=$ $2000 \mathrm{~cm} 3$ when $x=5 \mathrm{~cm}$ (see Figure 3)

It means that the values of $\mathrm{x}$ and $\mathrm{V}$ to be found are integers. This choice provides an interesting and easy to imagine answer for junior high school students. However, the value of $x=5$ is not easy to detect when only four specific boxes are studied. Hence,it encourages different answers within and between groups. Therefore, the students and the groups will have opportunities to discuss with each other if the teaching process is designed according to the fourth strategy of Radford \& Demers.

\subsection{How to Collect and Analyze Data}

- Data was collected from writing and recording products of students and textbooks. They were analyzed as follows:

- Analyze the textbooks to choose and build a solving problem. The selected problem should have the potential to develop activity with the material. Therefore, the solving problem would be suitable for the aim of the curriculum, especially in line with STEM education. 
- Analyze a priori. This analysis is conducted before the experiment and allows us to calculate the pedagogic options to archive our goal.

- Analyze a posteriori. This analysis shows what happened in the experiment compared with the estimates in the a priori analysis.

\subsection{How to Organize Teaching Activities}

The students are divided into pairs. Each pair of students in the group will be given six sheets of $30 \mathrm{~cm}$ s quare paper and 1 set of tools (scissors, a ruler with tape, tape, and pocket calculator).

Students are organized to work as follows:

Step 1: (5 minutes): Teacher introduces the problem.

Step 2 (30 minutes): Each pair will create four boxes, select the box with the most massive volume, then answer some questions. Groups will submit their best work to the teacher with the answer sheet 1 (see Appendix).

Step 3 (10 minutes): The pairs will exchange group work in the answer sheet 1 for the first time. The group that receives the results of the other groups will check the answers and write comments.

Step 4 (10 minutes): Return the answer sheet land comments sheet to the original group. Groups will revise the answers (if needed) after reading comments from other pairs.

Step 5 (20 minutes): The pairs continue to work on the volumetric function by converting to other representations.

Step $6 \quad(10$ minutes $)$ Teachers organize institutionalization.

\section{Results and Discussion}

Analysis of data collection (writing and recording products) allows the recognition of signs which correspond to communication standards of NTCM (2000).

\subsection{Communicating Students' Mathematical Thinking Coherently and Clearly to Peers}

Students made boxes and measured the box size to calculate the volume. Communication in pairs helps students reinforce the idea of measuring dimensions to calculate the volu me. Th is helps them feel about the change in volume according to the "dimensions" of the box.

"S3: How to calculate the volume?

S4: Length multiplied by the width and multiplied by the height

S3: What is the height?

S4: That is $\mathrm{x} .4 \mathrm{~cm}$.

S3: Oh. How much is this edge? Measure that $22 \mathrm{~cm}$.

S4: Then the other side is also $22 \mathrm{~cm}$.

S3: Why is that? A rectangular box?

S4: Yes, but the bottom is square at first. We cut each corner into $4 \mathrm{~cm}$, the edges must be equal?
S3: Yes. So this is 22 times 22 times 4 equals $1936 \mathrm{~cm}^{3}$. S4: OK. Let's measure otherboxes."

[Excerpts from the discussion of pair 2]

\subsection{Organizing and Consolidating Students Mathematical Thinking through Communication}

Communication helps students detect and reinforce ideas about the change in length, width and finally the volume depending on the length $\mathrm{x}$

"S5: What is this question 2.3? $x$ changes then what changes?

S6: That height change. $x$ is the height

S5: Yes. So do the length and width change?

S6: Yes. Cut evenly at each corner, and the edges are also shortened.

S5: All right. Fill it out.

S6: Next. The formula for calculating $V$ by $x$ goes .

S5: Isn't long-term replication high?

S6: Not possible. Calculate $\mathrm{V}$ by $\mathrm{x}$. There must be $\mathrm{x}$ in the formula.

S5: Yes. So what now? Or is it length times width and multiplies $\mathrm{x}$ ?"

[Excerpts from the discussion of pair 3]

\subsection{Using the Mathematical Language to Express Mathematical Ideas Precisely}

Finding algebraic formulas that show the dependence of volume on length $\mathrm{x}$ is not easy for every student. Couple exchanges help them adjust and find the exact mathematical formula.

"S9: What's this formula writing like?

S10: Calculating $\mathrm{V}$ in $\mathrm{x}$ must have $\mathrm{x}$ in the formula?

S9: Yes. In my opinion, it is $(30-x)$. $(30-x) . x$

S10: Why is that? Why $30-\mathrm{x}$ ? Not understand.

S9: That's it, cut each corner $\mathrm{x} \mathrm{cm}$. Isn't that $30-\mathrm{x}$ ?

S10: So it must be $30-\mathrm{x}-\mathrm{x}$ ? Each edge was cut at the two ends.

S9: Yes? How intelligent! So $(30-x-x) \cdot(30-x-x) \cdot x$

S10: Then write $(30-2 x)$. (30 - 2x) .x for brevity.

S9: Ok. Agree so."

[Excerpts from the discussion of pair 5]

\subsection{Analyzing and Evaluating Others' Mathematical Thinking and Strategies}

The learn ing process based on Radford\&Demers (2004) strategy 4 gives students the opportunity to review and evaluate their peers'opinions.

"S1: The way to calculate the volume of this group is the same as mine.

S2: Oh, that's right. Then calculate the volume of these boxes.

S1: Incorrect. Why?

S2: I don't get it. Recalculate them. 
S1: Why is the same formula for calculating volumetric results different?

S2: Yes. They manipulate wrongly on the calculator. Just recalculate!

S1: You see if the statements below are correct.

$\mathrm{S} 2$ : Question 2.3 is wrong. The variable $x$ is greater than 0 and smaller than 16 .

S1: Yeah, fix it."

[Excerpts from the discussion of pairs 1]

Moreover, students also have many opportunities to consider their own opinions. As such, students have the opportunity to develop metacognition.

"S3: they predict with $\mathrm{x}=10 \mathrm{~cm}$, there is the biggest volume.

S4: How could that be? That is wrong if $x=10 \mathrm{~cm}$ then $\mathrm{V}=1000 \mathrm{~cm}^{3}$.

S3: So that proves the volume formula is wrong?

S4: But it's like our formula. So is our formula wrong? Let's consider it again."

[Excerpts from the discussion of pairs 2]

\section{Conclusions}

In order to obtain the educational objective of developing mathematical communication competence for students, the teacher must know how to design and implement teaching process so that his students have opportunities to discuss and communicate with each other. The fourth strategy of Radford and Demers (2004) applied in our case study provided students with a learning environment in which mathematical communication was enhanced. Some lessons we drew from the case study to apply the fourth strategy successfully are:

- Math problems or learning tasks assigned to students must stimulate learning curiosity for students; they are interested in solving the problem.

- Math problems or learning tasks assigned to students must be open and have many answers that students have to discuss to give opinions and arguments to defend their opinions;

- The learning atmosphere must be open and democratic so that students feel free and confident when expressing their opinions.

- Teachers play an advisory and support role; do not impose their own opinion on the students.

From the results of the study, in the next time, we will undoubtedly introduce it to mathematics teachers and pedagogical students in educational universities of Vietnam.

\section{Appendix}

The answer sheet 1

Pair: ..Names of members
1) Create 4 boxes of different volumes and fill the measurements in the table

\begin{tabular}{|l|l|l|}
\hline & $\mathrm{x}(\mathrm{cm})$ & $\mathrm{V}\left(\mathrm{cm}^{3}\right)$ \\
\hline Box 1 & & \\
\hline Box 2 & & \\
\hline Box 3 & & \\
\hline Box 4 & & \\
\hline
\end{tabular}

Explain how to calculate the volume of a bo $\mathrm{x}$ in the table above:

2) Write answers to some of the following questions:

i) What is the variable $\mathrm{x}$ in the above table of a box?

ii) What is the value of the variable $\mathrm{x}$ limited to? (Stating specific values)

iii) When does the variable $\mathrm{x}$ change which quantities of the boxchange? (Indicates at least 3 quantities )

3) Write the formula for calculating the volume V by the variable $\mathrm{x}$ :

4) Draw pairs of points (x, V) on the coordinate system and then join them together.

Predict the value of $\mathrm{x}$ so that $\mathrm{V}$ is the

largest:

\section{REFERENCES}

[1] Hartle R. T, Baviskar S., and Smith R. (2012). Field Guide to Constructivism in the College Science Classroom: Four Essential Criteria and a Guide to their Usage. Bioscene , Volume 38(2) December 2012

[2] Le Do, H. T. (2018). Promoting mathematical communication in the teaching of function in junior high school. Master Thesis of Education. Education University of HCM City.

[3] Loc, N.P (2008) Sự “thích nghi” trí tuệ trong quá trình nhận thức theo quan điểm của J. Piaget, Tạp chí Giáo dục,(183), 
$2008 \operatorname{tr}, 11-13$.

[4] Loc, N.P. (2019). Applying Piaget's Adaptive Idea in Teaching Mathematics: A Teaching Model, International Journal of Scientific \& Technology Research volume 8, issue 10, October, 2019, ISSN 2277-8616

[5] Loc, N. P, \& Hang, N.T.A. (2019). Using Adaptation -Based Teaching into Teaching the Parametric Equation of a Straight Line in a Plane, International Journal of Scientific \& Technology Research volume 8, issue 12, December 2019 ISSN 2277-8616

[6] Ministry of Education and Training. (2018). General Education Curriculum. Ha Noi.

[7] Ministry of Education and Training. (2018). The curriculum of Mathematics. Ha Noi.

[8] National Council of Teachers of Mathematics. (2000). Principles and Standards for school mathematics. Reston, VA: Author.

[9] Radford L et Demers G. (2004). Communication et apprentissage Repères conceptuels et pratiques pour la salle de classe de mathématiques. Imprimeur de la Reine pour l'Ontario.

[10] Stanny C. J., Use Elements of Cognitive Constructivism to Design Effective Learning Activities Center for University Teaching, Learning, and Assessment, University of West Florida

(https://ctl.by u.edu/tip/use-elements-cognitive-constructivi sm-design-effective-learning-activities, 5/9/2019)

[11] Vygotsky, L.S. (1962). Thought and language (E. Hanf-mann\& G. Vakar, Trans.). Cambridge, MA: MIT Press.

[12] Vygotsky, L. S. (1978). Mind in Society: the Development of Higher Psychological Processes. Cambridge, MA: Harvard University Press. 